7. Child Lang. 4I (20I4), 8I I-84I. (C) Cambridge University Press 20I3. The online version of this article is published within an Open Access environment subject to the conditions of the Creative Commons Attribution-NonCommercial-ShareAlike licence $<$ http://creativecommons. org/licenses/by-nc-sa/3.०/> The written permission of Cambridge University Press must be obtained for commercial re-use.

doi:10.1017/So3050009130001 84

\title{
Number dissimilarities facilitate the comprehension of relative clauses in children with (Grammatical) Specific Language Impairment*
}

\author{
FLAVIA ADANI \\ Department of Linguistics, University of Potsdam
}

MATTEO FORGIARINI AND MARIA TERESA GUASTI

Department of Psychology, University of Milano-Bicocca

AND

HEATHER K. J. VAN DER LELY

Department of Psychology, Harvard University and Psychological Sciences

Research Institute, Université Catholique de Louvain

(Received I 9 fune 20 I - Revised 22 November 20 I I - Accepted Iо March 2013-

First published online 28 fune 2013)

\section{A BSTRACT}

This study investigates whether number dissimilarities on subject and object DPs facilitate the comprehension of subject- and object-extracted centre-embedded relative clauses in children with Grammatical Specific Language Impairment (G-SLI). We compared the performance of a group of English-speaking children with G-SLI (mean age: I2; II) with that of two groups of younger typically

[*] We would like to thank the children who took part in the study, their parents, and the staff from the following schools: Dawn House School, Moor House School, and Radlett Primary School. We are grateful to Nichola Gallon, Angela Pozzuto, and Chloë Marshall for their help in designing the experiment and helping out with testing, to Mike Coleman for sharing his technical expertise, and to Chloë Marshall and Outi Tuomainen for their comments on a previous version of the manuscript. All remaining errors are of course our own. FA was supported by a PhD scholarship awarded by the University MilanoBicocca; HvdL was supported by The Wellcome Trust Grant (o637 I 3); MTG, MF, and HvdL were supported by the grant Cross-linguistic Language Diagnosis (CLAD, I 35295-LLP-I-2007-UK-Ka I-KaISCR). The funders had no role in study design, data collection and analysis, the decision to publish or the preparation of the manuscript. Address for correspondence: Heather K. J. van der Lely, Department of Psychology, Harvard University. William James Hall, 33 Kirkland Street, Cambridge MA, USA.: e-mail: hvdlely@wjh.harvard.edu. 
developing (TD) children, matched on grammar and receptive vocabulary, respectively. All groups were more accurate on subjectextracted relative clauses than object-extracted ones and, crucially, they all showed greater accuracy for sentences with dissimilar number features (i.e., one singular, one plural) on the head noun and the embedded DP. These findings are interpreted in the light of current psycholinguistic models of sentence comprehension in TD children and provide further insight into the linguistic nature of G-SLI.

\section{INTRODUCTION}

Children with developmental language disorders, especially those with Specific Language Impairment (SLI), are notoriously impaired in their comprehension of syntactically complex structures (Bishop, I 997 ; Leonard, I 998). Since at least Stark and Tallal (i98I), SLI has been considered a heterogeneous disorder and several scholars have identified subgroups of children with a more selective disorder in one or more language components (Conti-Ramsden \& Botting, I999; Conti-Ramsden, Crutchely \& Botting, I 997; Friedmann \& Novogrodsky, 20I I ; van der Lely i 996a, 2005). This paper continues the investigation into the nature of the deficit in the SLI subgroup known as G(rammatical)-SLI (van der Lely, I 998, 2005). We are cautious in extending the linguistic characterization of G-SLI to other subgroups, yet the nature of the deficit in children with G-SLI appears to be consistent with SLI more generally in English and various other languages (Friedmann \& Novogrodsky, 2007; Jakubowicz \& Tuller 2008; Stavrakaki \& van der Lely, 2010). We aim to establish whether the performance of children with G-SLI improves as a function of the morphological properties of linguistic constituents that appear in relative clauses ( $\mathrm{RC}$, henceforth). Specifically, we focus on number dissimilarity between subject- and object-DPs that occupy argument positions in the main and/or embedded clause.

Recent investigations of unimpaired adults (Gordon, Hendrick \& Johnson, 200I) and TD children (Adani, van der Lely, Forgiarini \& Guasti, 2010; Arnon, 2010; Friedmann, Belletti \& Rizzi, 2009) have shown that various types of dissimilarities facilitate object-extracted RC comprehension. Turning to SLI, there is substantial cross-linguistic evidence that comprehension of RCs is impaired in these children (Contemori \& Garraffa, 2010; Friedmann \& Novogrodsky, 2004; Håkansson \& Hansson, 2000; Schuele \& Nicholls, 2000; Stavrakaki, 200I), but it is less clear whether nominal and verb morphology is also impaired (Bortolini, Leonard \& Caselli, I998; Clahsen, Bartke \& Gollner, I997; Leonard, McGregor \& Allen, I992; Oetting \& Rice, I993). In this paper, we address the question: Are children with G-SLI able to use number morphology to facilitate 
comprehension of RCs? The answer to this question will (a) provide a more detailed characterization of which linguistic abilities are impaired or spared in G-SLI (and possibly in SLI) and (b) identify those properties that can enhance syntactic knowledge in speech and language rehabilitation. To our knowledge, our study is the first attempt to investigate the interaction of sentence complexity and morphosyntactic features in SLI. A sample of sentences under investigation is given in (I); here and throughout the paper, the position of the head noun as subject or object of the embedded verb is indicated within angled brackets ' $\langle>$ ':

(I) a. The goat that $<$ goat $>$ is washing the cat has climbed onto the stool.

b. The goat that $<$ goat $>$ is washing the cats has climbed onto the stool.

c. The goat that the cat is washing $<$ goat $>$ has climbed onto the stool.

d. The goat that the cats are washing $<$ goat $>$ has climbed onto the stool.

In ( $\mathrm{ra} \& \mathrm{~b}$ ) the RC head (the goat) is the subject of both the main clause and the RC (hereafter, SS) whereas in ( $\mathrm{rc} \& \mathrm{~d}$ ) the RC head is the subject of the main clause and the object of the RC (hereafter, SO). We aim to investigate whether children with G-SLI are sensitive to number feature dissimilarities of subject and object DPs that occupy argument positions in the sentence. We are working within the Computational Grammatical Complexity (CGC) hypothesis developed by van der Lely and colleagues (Marshall \& van der Lely, 2007; van der Lely, I 998, 2005; inter alia). These authors argue that children with G-SLI are impaired in computing hierarchical structures within syntax, morphology, and phonology. Within syntax, the CGC hypothesis claims that the impairment in G-SLI is restricted to non-local dependencies at the clause level, which are derived through the application of movement operations. Their subsequent deficit includes the use of subordinate clauses (van der Lely, I998), wh-question formation (Marinis \& van der Lely, 2007; van der Lely \& Battel, 2003), and the assignment of thematic roles in passive sentences (van der Lely, I 996a). In contrast to these difficulties, other local syntactic dependencies, such as Specifier-Head agreement (e.g., the relation between determiner-noun within the DP and subject-verb within the clause), are spared (Stavrakaki and van der Lely, 20ı०; van der Lely ı 998; van der Lely \& Stollwerck, I 997). As for the current study, the CGC hypothesis predicts impaired comprehension of $\mathrm{SS}$ and particularly of $\mathrm{SO}$, since both structures are derived by syntactic movement but the presence of non-canonical word order in SO makes any semantic strategy less likely to lead to success. The CGC hypothesis also predicts that structural dependencies that are NOT derived by movement are spared. Hence, children with G-SLI will be able to check agreement relations such as person or number within DPs, that is, between the determiner and the head noun in a Specifier-Head 
configuration. Thus, the presence of mismatching number features on DPs (and related verbs) is predicted to facilitate the correct interpretation of RCs in children with G-SLI.

We now turn to reviewing the relevant psycholinguistic literature about adults and TD children which forms the basis of our study.

\section{Facilitation effects in RC comprehension: converging evidence from children and adults}

Current psycholinguistic research with adults indicates that $\mathrm{RC}$ processing can be manipulated experimentally, using a variety of language properties. For example, using the self-paced reading technique (Gordon et al., 200I), adults were significantly faster and more accurate in RCs such as (2), where the embedded DP was a pronoun (you), a proper name (Foe) or a quantifier (everyone), rather than when it was a definite description (the lawyer):

(2) The barber that the lawyer/you/Joe/everyone admired < barber $>$ climbed the mountain.

The effect found in adult on-line processing is also present in children's off-line comprehension. Hebrew-speaking children demonstrated higher accuracy for object RCs where the head noun was a definite DP (the girl) and the embedded DP was a constituent of a different type, such as a personal pronoun (Arnon, 2010), an interrogative pronoun, or impersonal arbitrary pro (Friedmann et al., 2009) (the following examples are English adaptations of the original Hebrew stimuli of Arnon, 2010):

(3) a. What color are the shoes of the girl that the nurse is drawing $<$ girl $>$ ?

b. What color are the shoes of the girl that I am drawing < girl > ?

Four-year-olds were significantly more accurate in (3b) than in (3a). Grillo (2008) and Friedmann et al. (2009) interpreted a facilitation in sentential contexts similar to (2) and (3) as the result of a stricter application of Relativized Minimality (Rizzi, I990, 2004). They propose that due to an increased language processing load in a context of impaired or immature language systems, adults with aphasia (Grillo, 2008) and young TD children (Friedmann et al., 2009) struggle to compute the syntactic relation between the DP head and its copy, when the intervening embedded subject DP (the lawyer in (2); the nurse in (3)) is structurally similar to the moved constituent. The approach put forward by Grillo and colleagues, on the one hand, and Friedmann and colleagues, on the other, differ in some details. Grillo assumes feature under-specification to be at the origin of this difficulty in aphasia, whereas Friedmann and colleagues capitalize on the internal structure of these constituents. In particular, Friedmann et al. (2009) showed that four-year-old Hebrew-speaking children perform at chance

\section{I 4}


level in $(4 \mathrm{a}, \mathrm{b})$ but are significantly more accurate in $(4 \mathrm{c}, \mathrm{d})$ (the following examples are English adaptations of the original Hebrew stimuli used by Friedmann et al., 2009):

(4) a. Show me the girl that the nurse is wetting $<$ girl $>$.

b. Which girl does the nurse wet < girl $>$ ?

c. Show me the girl that someone is wetting $<$ girl $>$.

d. Who does the nurse wet < girl > ?

In order to explain this response pattern, Friedmann et al. (2009) point out that the relative head/wh-phrase and the intervening subject have a set of disjoint features in $(4 \mathrm{c} \& \mathrm{~d})$ but not in $(4 \mathrm{a} \& \mathrm{~b})$, due to the simultaneous presence of a lexically restricting feature $[+\mathrm{NP}]$ on both constituents (e.g., they contain a noun girl and nurse and so they are both specified with the feature $[+\mathrm{NP}])$. Friedmann et al. argue that it is the simultaneous presence of this feature on both constituents which makes (4a) and (4b) hard to interpret. However, this difficulty disappears when only one of the two constituents is specified with the $[+\mathrm{NP}]$ feature. In $(4 \mathrm{c} \& \mathrm{~d})$, the absence of the lexical restriction on one of the two constituents makes the embedded subject (someone in $(4 \mathrm{c})$, who in $(4 \mathrm{~d})$ ) less prone to interpretation as a member of the relation between the $\mathrm{RC}$ head (in c) or the wh-pronoun (in $\mathrm{d}$ ) and the copy.

In a study with Italian-speaking TD children, Adani et al. (2010) challenged the claim that object RCs with two full DPs are all equally difficult for children. Building on Friedmann et al. (2009), Adani et al.'s (2010) proposal integrates the internal properties of the lexical restriction $[+\mathrm{NP}]$. Italian-speaking children (age : 5-9) were assessed on their comprehension of object RCs that differed according to whether the subject and object DPs had the same (5a) or different $(5 \mathrm{~b})$ number properties $(\mathrm{SG}=$ singular; $\mathrm{PL}=$ plural) or the same $(5 \mathrm{c})$ or different $(5 \mathrm{~d})$ gender properties $(\mathrm{M}=$ masculine $; \mathrm{F}=$ feminine $)$ :

(5) a. Il leone che il gatto sta toccando $<$ leone $>$ è seduto per terra.

The lion-SG that the cat-SG is touching <lion $>$ is sitting on the ground

b. Il leone che i coccodrilli stanno toccando <leone $>$ è seduto per terra.

The lion-SG that the crocs-PL are touching $<$ lion $>$ is sitting on the ground

c. Il gatto che il topo sta lavando <leone $>$ è salito sullo sgabello. The cat-M that the mouse-M is washing $<$ lion $>$ has climbed onto the stool

d. Il gatto che la capra sta lavando <leone $>$ è salito sullo sgabello The cat-M that the goat-F is washing $<$ lion $>$ has climbed onto the stool 
Overall, children were significantly more accurate in mismatch-feature-value conditions $(5 \mathrm{~b} \& \mathrm{~d})$, but it was also shown that the size of this effect was larger in the number condition $(5 \mathrm{~b})$ than in the gender condition. In order to capture this asymmetry, Adani et al. proposed that it is not $[+\mathrm{NP}]$ per se that increases the ORC difficulty but that different features generate dissimilarity effects with different sizes. They argued that the prominence of these effects was related to the structural nature of the features. That is, independent functional heads such as number trigger a stronger distinctive effect, whereas lexicalized features such as gender in Italian contribute to the computation of dissimilarity to a lesser degree (Carminati, 2005).

The current study builds on and extends this body of work by investigating $\mathrm{RC}$ comprehension in children with G-SLI. There has been much research investigating inflectional morphology in children with SLI and their ability to comprehend and produce RCs and wh-questions. In the next two sections, we review the existing literature about morphological abilities and comprehension of movement-derived sentences in children with (G-)SLI.

\section{Morphological abilities in children with $(G-) S L I$}

The study of morphological impairments in SLI has received considerable attention in the literature, particularly with respect to tense marking. It is generally agreed that English-speaking children with SLI perform significantly poorly on tense morphology (Leonard et al., I992; Rice \& Wexler, I996), with regular verbs being affected more severely than irregular ones (van der Lely \& Ullman, 200I). However, the findings regarding another morphological operation, namely agreement, show less consensus. We use the term 'agreement' to refer to both subject-verb agreement (e.g., person/number in English) within a clause (the child sleeps vs. the children sleep) and determiner-noun agreement (e.g., number in English) within a DP (a dog vs. some dogs). With respect to subject-verb agreement, some scholars consider that children with SLI have problems with inflected lexical verbs (Clahsen et al., I997; Leonard et al., I 992), although inflection on functional verbs (e.g., auxiliary verbs in French) is less affected (Jakubowicz, 2003). With respect to agreement within the DP, the picture is even more unclear. On the one hand, plural morphology on nominal constituents (plural -s) is considered to be impaired in SLI (Bortolini et al., I 998; Clahsen et al., I997; Leonard et al., I992). On the other hand, however, children with SLI showed a productive plural system (Oetting \& Rice, I993). Moreover, language rehabilitation was found to be more successful when children had prior knowledge of noun pluralization and subject-verb agreement (Pawlowska, Leonard, Camarata, Brown \& Camarata, 2008). 
The CGC hypothesis predicts a relative sensitivity in children with G-SLI for agreement relations because they are derived via a specifier-head relation (Stavrakaki \& van der Lely, 20ıо; van der Lely, I998). This predicted sensitivity to number agreement is tested, in the current study, against another grammatical operation, namely wh-movement. In contrast to number agreement, syntactic dependencies involving movement of constituents across other phrases are predicted to be impaired by the CGC hypothesis. In the next section, we will provide a detailed characterization of how children with (G-)SLI deal with two types of movement-derived structures, namely relative clauses and wh-questions.

\section{Cross-linguistic studies on comprehension and production of movement-derived sentences in children with (G-)SLI}

Friedmann and Novogrodsky tested comprehension (Friedmann \& Novogrodsky, 2004) and production (Novogrodsky \& Friedmann, 2006) in a group of Hebrew-speaking children with $\mathrm{S}$ (yntactic)-SLI ${ }^{1}$ ( $\mathrm{N}=\mathrm{I}$ \%; age range 7;3-I I ; 2 in the comprehension task and $\mathrm{N}=\mathrm{I} 8$; age range $9 ; 3-\mathrm{I} 4 ; 6$, in the production task). The children were tested on right-branching subject and object RCs. Compared to their controls, children with S-SLI were significantly impaired in their production and comprehension of object RCs, but no difference was found in subject RCs. Friedmann and Novogrodsky argue that children with S-SLI fail to assign the correct thematic role to a moved constituent. Furthermore, Levy and Friedmann (2009) describe a therapy case study of a Hebrew-speaking child with S-SLI targeting wh-movement (among other types of movement) using a metalinguistic methodology. The abstract notion of syntactic movement was taught to the child by means of visual illustrations. Then, the intervention moved towards the explicit teaching of syntactic movement in orally presented sentences. Wh-movement was explicitly taught using three structure types: topicalizations, object RCs, and subject RCs. At the end of the therapy, the child showed substantial improvement in all structures compared with the baseline and there was also an improvement in structures that were not explicitly treated, namely wh-questions. This improvement was maintained for at least ro months.

In a series of studies conducted with Greek-speaking children, Stavrakaki assessed comprehension $(\mathrm{N}=8$; age range: $5 ; 4-9 ; 4)$ as well as production $(\mathrm{N}=8$; age range: $6 ; \mathrm{I}-\mathrm{IO} ; 0)$ of $\mathrm{RCs}$ and wh-questions (Stavrakaki, 2001, 2002), using an act-out technique. In the comprehension study,

[I] Whereas both S-SLI and G-SLI subgroups have deficits in syntax and morphology, children with G-SLI typically have deficits in phonology too, whereas S-SLI do not (van der Lely, 2005). 
children with SLI were tested on seven construction types, which showed different properties in terms of locus of embedding (centre-embedded vs. right-branching), subject position (pre-verbal vs. post-verbal), and presence or absence of clitic pronoun. The results revealed that the performance of children with SLI differed from their language-matched peers' performance on non-canonical word order structures. In a production task, rather than producing RCs, the children with SLI and some TD children produced simple active sentences and coordinated structures. However, only the children with SLI produced RCs with a missing head. Stavrakaki concluded that children with SLI are unable to use syntactic operations such as movement and have a deficit that mainly affects this computational component of language.

Two further studies investigated both the comprehension and the production of RCs in one group of young children with SLI. First, Håkansson and Hansson (2000) carried out a longitudinal study on RC production and comprehension in a group of Swedish-speaking children with SLI (N= IO; age range: 4;0-6;3). They found that these young children with SLI and younger language-matched TD children did not differ in their RC comprehension. However, in production, children with SLI omitted the relative complementizer, whereas the TD children used it. In a recent study, comprehension and production of RCs was assessed in a small group of Italian-speaking children with SLI $(\mathrm{N}=4$; age range: 4:5-5:9) by Contemori and Garraffa (2010). Production of object RCs was significantly impaired in children with SLI, compared to language- and age-matched controls. While TD children adopted various strategies to avoid the production of object RCs (such as passive subject RCs or object RCs with resumptive pronoun or resumptive DP), children with SLI were unable to construct any RC. Contemori and Garraffa (2010) attributed the more accurate performance in comprehension shown by children with SLI to the application of a 'first NP' = 'Agent' heuristic.

Finally, in a longitudinal case study of three English-speaking children, Schuele and Nicholls (2000) analyzed spontaneous language samples and an elicited RC task. The three children with SLI omitted obligatory relative markers (that/who/which) in subject RCs (e.g., she's get all the dishes need to be washed) and one of them selected the wrong relative marker in object RCs (e.g., she told everything *what she bought for you, where the star '*' indicates the inappropriate relative marker for Standard American English). Based on these results, they concluded that children with SLI are impaired in both subject and object RCs. They interpreted this as impairment in using grammatical morphemes such as free-standing closed-class forms.

Our study provides the first experimental investigation of RC comprehension in English-speaking children with (G-)SLI. However, another syntactically complex construction, wh-questions, has been 
extensively investigated in children with G-SLI. As with RCs, wh-questions are also derived via movement, a syntactic operation which establishes a relation between the position in which the wh-constituent (who in (6)) is pronounced (this position is also called FILLER) and the position where the referent for the wh-constituent (indicated by $<$ rabbit $>$ in (6)) is interpreted (this position is also called GAP):

(6) Balloo gives a long carrot to the rabbit. (context)

Who did Balloo give the long carrot to < rabbit $>$ at the farm?

Given this structural similarity, the acquisition of RCs and wh-questions is often compared in developmental research. In the remaining part of this section, we will summarize previous findings on the on-line processing of wh-questions in children with G-SLI.

Marinis and van der Lely (2007) conducted an on-line study to assess the processing of wh-questions. A group of children with G-SLI ( $N=14$; age range: $10 ; 2-17 ; 2$ ) and two groups of TD controls (receptive vocabulary/ memory and chronological age) participated. Children with G-SLI were significantly slower than their age-controls, but not slower than their vocabulary-controls. Furthermore, whereas both the age- and vocabularycontrols showed reactivation of the moved wh-constituent at the gap position, indicating that they had processed wh-questions through syntactic filler-gap dependencies, the children with G-SLI showed a reactivation of the moved wh-constituent only at the verb (give in (6)). The authors argue that children with G-SLI fail to establish a syntactic filler-gap dependency and that they interpret wh-questions via lexical-thematic information. A recent electro-physiological investigation further supports this view. Fonteneau and van der Lely (2008) investigated the processing of syntactic and semantic violations in a group of children and teenagers with G-SLI $(\mathrm{N}=\mathrm{I} 8$; age range: $\mathbf{I 0 - 2 I})$ and in three groups of languagecontrols, chronological age-controls, and adults, using the ERP technique. They found that the structural relations between the wh-word (who/what) and a DP that filled the first potential gap were unexpected and elicited an Early Left Anterior Negativity (ELAN) in all the control groups. However, such negativity was not activated in the children with G-SLI. The ELAN is reputedly specific to syntactic violations (Friederici, Hahne \& Saddy, 2002). In contrast to the controls, the syntactic violation elicited a significant negativity around $400 \mathrm{~ms}$ with a right posterior distribution in the children with G-SLI. These electro-physiological brain responses were interpreted as revealing a selective impairment to the neural circuitry that is specific to grammatical processing in G-SLI. Furthermore, the participants with G-SLI appeared to be partially compensating for their syntactic deficit by using neural circuitry associated with semantic processing. 
In summary, difficulties in $\mathrm{RC}$ comprehension are attested crosslinguistically in children with SLI. Children with G-SLI have not yet been tested on RCs, but given the hierarchical syntactic dependencies required for their understanding, as with wh-questions, the CGC hypothesis predicts that children with G-SLI will be impaired on them. Furthermore, the grammatical properties of syntactic constituents influence the comprehension of RCs in adults and TD children, but these properties have not been manipulated in a study of children with (G-)SLI. In the remaining part of the paper we will present how the role of number feature was tested in the comprehension of RCs in children with G-SLI.

\section{METHOD}

\section{Participants}

The group of children with G-SLI consisted of twelve participants (6 boys), aged $9 ; 5^{-\mathrm{I}} 6 ; \mathrm{O}(\mathrm{M}=\mathrm{I} 2 ; \mathrm{I} \mathrm{I} ; \mathrm{SD}=25 \cdot 88$ in months).

To be classified as G-SLI, the children had to first meet the criteria for SLI, and second show persistent deficits in syntax and morphology from the age of nine onwards. The selection is based on three specialized tests that probe core aspects of morphosyntax (passives, agreement, and tense). Children with G-SLI have to make $20 \%$ or more errors on these specialized tests, where TD children rarely make any after age six (van der Lely, 2005).

Hence, the children included in this study all had a professional diagnosis of SLI and were attending special language schools or language units. Their non-verbal cognitive abilities fell within the normal range as measured by the Raven's Progressive Matrices (Raven, I998) (mean non-verbal IQ

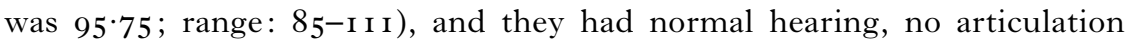
difficulties, and appropriate emotional and social behaviour. All children had a $z$-score of at least $-\mathrm{I}_{5} 5$ (corresponding to $-\mathrm{I}_{5} \mathrm{SD}$ ) on two or more of the following standardized language tests: Test for Reception of Grammar (Bishop, 2003), British Picture Vocabulary Scales (Dunn, Dunn, Whetton \& Pintilie, I982), the sentence repetition subtest of the Clinical Evaluations of Language Fundamentals (Semel, Wiig \& Secord, r995), Test of Word Finding (German, 2000). An overview of scores of standardized tests for each participant is reported in Table $\mathbf{I}$.

In addition to these standardized tests, all participants in this study have persistent problems on a range of non-standardized tests that tap into specific grammatical aspects. These include the Verb Agreement and Tense Test (van der Lely, 2000), the Test of Active and Passive Sentences (van der Lely, I996b), and the Advanced Syntactic Test of Pronominal Reference (van der Lely, I 997). Each participant made $20 \%$ or more errors on at least one specialized grammatical test, as illustrated in Table I. 
TABLE I. Scores on standardized (in Z-scores) and non-standardized (in \% correct) tests for children with G-SLI (the grey shade highlights a z-score of $-\mathbf{I} \cdot 5$ (or lower) and an accuracy of $80 \%$ (or lower))

\begin{tabular}{|c|c|c|c|c|c|c|c|c|}
\hline & $\begin{array}{c}\mathrm{RPM} \\
z\end{array}$ & $\begin{array}{c}\text { TROG-2 } \\
z\end{array}$ & $\begin{array}{c}\text { BPVS } \\
z\end{array}$ & $\begin{array}{c}\text { CELF-3 } \\
z\end{array}$ & $\begin{array}{c}\text { TWF-2 } \\
z\end{array}$ & $\begin{array}{c}\text { VATT } \\
\%\end{array}$ & $\begin{array}{c}\text { A-STOP } \\
\%\end{array}$ & $\begin{array}{c}\text { TAPS } \\
\%\end{array}$ \\
\hline $\mathrm{S}_{\mathrm{I}}$ & 0.73 & $-I \cdot 60$ & -0.07 & $-2 \cdot 00$ & -0.60 & 43 & $8 I$ & 86 \\
\hline $\mathrm{S}_{2}$ & 0.40 & $-I \cdot 00$ & -0.33 & $-2 \cdot 33$ & $-2 \cdot 20$ & 68 & 60 & $5^{6}$ \\
\hline $\mathrm{S}_{3}$ & -0.47 & -0.87 & $-\mathrm{I} \cdot 53$ & $-2 \cdot 00$ & $-\mathrm{I} \cdot 67$ & 60 & 63 & 89 \\
\hline $\mathrm{S}_{4}$ & O.I 3 & -2.60 & $-I \cdot 60$ & $-2 \cdot 33$ & $-2 \cdot 60$ & 3 & 96 & $6 I$ \\
\hline $\mathrm{S}_{5}$ & -0.33 & $-\mathrm{I} \cdot 73$ & -0.60 & $-2 \cdot 00$ & -0.73 & 80 & IOO & $8_{3}$ \\
\hline S6 & -0.87 & -2.07 & $-2 \cdot 20$ & $-2 \cdot 33$ & -3.07 & I 3 & 54 & $\mathrm{~N} / \mathrm{A}$ \\
\hline $\mathrm{S}_{7}$ & $-I \cdot O 0$ & -0.80 & $-\mathrm{I} \cdot 67$ & $-2 \cdot 33$ & $-\mathrm{I} \cdot \mathrm{I} 3$ & 75 & 25 & $6 I$ \\
\hline $\mathrm{S} 8$ & -0.20 & $-I \cdot 60$ & -0.67 & $-\mathrm{r} \cdot 67$ & $-\mathrm{I} \cdot 33$ & 70 & $6_{3}$ & 72 \\
\hline S9 & -0.73 & -0.20 & $-2 \cdot 33$ & $-2 \cdot 00$ & $-\mathrm{I} \cdot 80$ & 30 & 88 & $5^{8}$ \\
\hline Sio & -0.73 & -0.33 & $-\mathrm{I} \cdot 53$ & $-2 \cdot 00$ & $-I \cdot 40$ & 80 & $5^{8}$ & $8 I$ \\
\hline S I I & 0.07 & $-I \cdot 93$ & $-2 \cdot 00$ & $-2 \cdot 33$ & $-\mathrm{I} \cdot 87$ & 65 & 46 & 47 \\
\hline $\mathrm{S}_{12}$ & -0.40 & $-I \cdot O ০$ & $-\mathrm{I} \cdot 87$ & $-2 \cdot 00$ & $-I \cdot 40$ & 35 & 92 & 89 \\
\hline Mean & -0.28 & $-I \cdot 3 I$ & $-\mathrm{I} \cdot 37$ & $-2 \cdot$ I I & $-\mathrm{I} \cdot 65$ & $5 I \cdot 67$ & $68 \cdot 83$ & $7 \mathrm{I} \cdot 2 \mathrm{I}$ \\
\hline $\mathrm{SD}$ & 0.53 & 0.73 & 0.76 & $0.2 \mathrm{I}$ & 0.72 & $26 \cdot 57$ & $22 \cdot 74$ & I 5.08 \\
\hline
\end{tabular}

NOTES : RPM : Raven's Progressive Matrices (Raven, I998); TROG-2: Test for Reception of Grammar (Bishop, 2003); BPVS: British Picture Vocabulary Scales (Dunn et al., I 982); CELF-3: Sentence Repetition subtest of Clinical Evaluations of Language Fundamentals (Semel, Wiig \& Secord, I995); TWF-2: Test of Word Finding (German, 2000); VATT: Verb Agreement and Tense Test (van der Lely, 2000); A-STOP : Advanced Syntactic Test of Pronominal Reference (van der Lely, I 997); TAPS: Test of Active and Passive Sentences (van der Lely, i $996 \mathrm{~b}$ ).

In line with a great deal of previous work by van der Lely and colleagues, we selected two groups of younger children who are matched on raw scores on either sentence understanding (hereafter grammar control group) or on receptive vocabulary (hereafter vocabulary control group). The use of two control groups allows one to independently determine the effects of vocabulary (an overall measure of language development) and grammar (a specific language component) on RC test performance. A summary of the group's details are given in Table 2 .

The grammar control group consisted of twelve children ( 5 boys, mean age $=6 ; 9 ; \mathrm{SD}=5.9 \mathrm{I}$ in months) who were matched to the children with G-SLI on the raw scores of a TROG test (Bishop, 2003) (independent sample $t$-test: $p=\cdot 69$ ). A second group of twelve children (3 boys, mean age $=8 ; 2 ; \mathrm{SD}=5 \cdot 12$ in months) was matched to the group of children with G-SLI on raw scores obtained on BPVS (Dunn et al., r 982) (independent sample $t$-test: $p=\cdot 55)$. The Grammar control group was significantly younger than the Vocabulary control group (independent sample $t$-test: $p<\cdot \circ \circ \mathrm{I})$. Receptive grammar and vocabulary in both language control groups were within the expected range of abilities for their ages, as shown in 
TA B LE 2. Mean ages, raw scores, and SD (in months) for each group

\begin{tabular}{|c|c|c|c|}
\hline & $\begin{array}{c}\text { G-SLI } \\
\mathrm{N}=\mathrm{I} 2 \\
\text { Mean (SD) }\end{array}$ & $\begin{array}{c}\text { GRAMMAR } \\
\mathrm{N}=\mathrm{I} 2 \\
\text { Mean (SD) }\end{array}$ & $\begin{array}{l}\text { VOCABULARY } \\
\begin{array}{c}\mathrm{N}= \\
=\text { I } 2 \text { Mean } \\
(\mathrm{SD})\end{array}\end{array}$ \\
\hline Age & I 2 ; I I (25.88) & $6 ; 9(5 \cdot 92)$ & $8 ;$ I $(5 \cdot$ I 2$)$ \\
\hline Range age & $9 ; 5-\mathrm{I} 6 ; 0$ & $6 ; \circ-7 ; 5$ & $7 ; 8-8 ;$ I I \\
\hline $\begin{array}{l}\text { Morphosyntax (TROG) } \\
\text { Raw scores }\end{array}$ & I $2 \cdot 83(2 \cdot 76)$ & I $3 \cdot 33(3 \cdot 26)$ & I $5 \cdot 42(\mathrm{I} \cdot 24)$ \\
\hline $\begin{array}{l}\text { Vocabulary (BPVS) } \\
\text { Raw scores }\end{array}$ & $86 \cdot 75(14 \cdot 25)$ & $75.08(\mathrm{I} 6.8 \mathrm{I})$ & $89 \cdot 5 \circ(7 \cdot 32)$ \\
\hline
\end{tabular}

NOTES: TROG: Test Receptive of Grammar (Bishop, 2003); BPVS: British Picture Vocabulary Scale (Dunn et al., I982).

Table 2. The grammar level of the Vocabulary control group was significantly more advanced than that of children with G-SLI (independent sample $t$-test: $p=\cdot 007)$, whereas the vocabulary level of the Grammar control group did not differ from that of children with G-SLI (independent sample $t$-test: $p=\cdot 08$ ).

Parental consent was obtained and the children were happy to take part in this study.

\section{Design}

Two experimental factors were manipulated: Sentence Type (SS vs. SO) and number Match (Match [M] vs. Mismatch [MM]). Table 3 illustrates the experimental design. For each sentence type (SS and SO), the RC head was singular and in the other half it was plural in the Match and Mismatch trials. Hence, plurality of the RC head was counterbalanced in each condition.

\section{Materials}

For each of these four conditions, there were twelve trials (6 with singular $\mathrm{RC}$ head and 6 with plural RC head), making forty-eight sentences in total. Eight verbs were used as main verbs (fall, sit, climb, jump, fly, enter, lie, slip) and they were paired with another eight transitive verbs in the embedded clause (pull, splash, wash, stroke, wave, push, comb, touch). All these verbs and some of the pictures used to depict them had been extensively piloted and used in previous work (Fonteneau \& van der Lely, 2008; Stavrakaki \& van der Lely, 20I0). We ensured that the same pair of verbs did not co-occur with the same pair of nouns. Nouns for subject and object DPs were all names of animals. The frequency of nouns used in Match or 


\begin{tabular}{lll}
$\begin{array}{l}\text { Sentence } \\
\text { type }\end{array}$ & DP match & \multicolumn{1}{c}{ Test sentence example } \\
\hline SS & M & $\begin{array}{l}\text { The cat that is washing the goat has climbed onto the stool. } \\
\text { The cats that are washing the goats have climbed onto the stool. } \\
\text { The cat that is washing the goats has climbed onto the stool. } \\
\text { The cats that are washing the goat have climbed onto the stool. }\end{array}$ \\
SO & M & $\begin{array}{l}\text { The hippo that the rhino is washing has climbed onto the stool. } \\
\text { The hippos that the rhinos are washing have climbed onto the stool. } \\
\text { The hippo that the rhinos are washing has climbed onto the stool. } \\
\text { The hippos that the rhino is washing have climbed onto the stool. }\end{array}$ \\
& MM &
\end{tabular}

NOTES: SS: subject relative clause; SO : object relative clause; M : Match; MM: Mismatch.

Mismatch conditions were compared using the Celex database and analysis revealed that there was no significant difference between conditions (SS sentences: $p=\cdot 967$; $\mathrm{SO}$ sentences : $p=\cdot 857)$. All sentences were prerecorded by a female native speaker of British English. In addition to the experimental sentences, a further twenty-four SS and twenty-four SO with DPs matching in number were administered. Hence, in total, there were seventy-two sentences with two singular constituents and twenty-four sentences with one singular and one plural constituent. ${ }^{2}$ From the first list of ninety-six sentences, a second list was then constructed in which the subject and object DPs were reversed. Thus, half of the participants were presented with List I, the other half were presented with List 2. The creation of two lists with reversed noun order produced a cross-over design which enabled us to control for potential confounding effects, e.g., for a particular noun being a more suitable subject (or object) over the others. The trial order was pseudo-randomized. Each sentence was paired with four pictures that represented all combinations between the actors in the sentence (subject and object DP) and the two actions (embedded and main verbs). The same characters and actions were depicted in each set of pictures. A sample of condition $I$ and condition 2 is given in Figure ( $\mathrm{Ia}$ ) and ( $\mathrm{Ib}$ ), respectively.

One of the pictures was correct and there were three distractor pictures. The distractor pictures were designed to provide insight into misinterpretations (see Response type coding section). The distractor and target picture positions on the screen were randomized.

[2] A reviewer raises the question whether such an imbalance might have had an effect on the results. We think this is not the case as, if it were so, the most frequent singular-only items should have been facilitated, something that definitely does not happen in our results. 


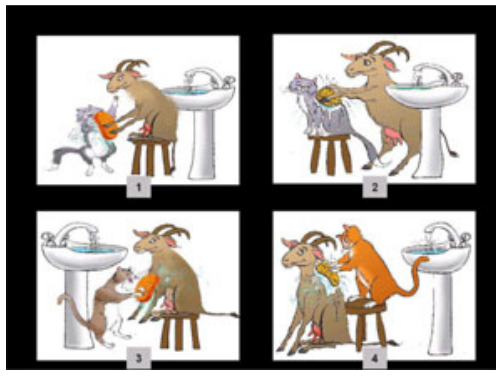

(a) Set of pictures paired with the trial The cat that is washing the goat has climbed onto the stool (Target: 4)

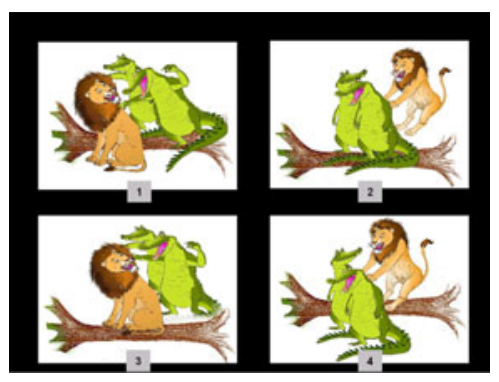

(b) Set of pictures paired with the trial The crocodiles that are touching the lion have climbed onto the trunk (Target: 1)

Fig. I. A sample of the experimental pictures.

\section{Procedure}

The experiment was programmed with E-Prime (Schneider, Eschman \& Zuccolotto, 2002) and administered using a Dell Latitude D5 Io laptop computer and SONY MDR-7509 headphones. Participants were instructed to look at the four pictures on the screen, listen carefully to the sentence, and then press one out of four keys on the keyboard. Each picture was linked to a number from one to four, which corresponded to the same number reported on each response key. Each response key was highlighted with bright-coloured stickers which corresponded to a picture number. Preliminary instructions emphasized the importance of looking carefully at all pictures and being accurate rather than fast.

Four practice trials preceded the presentation of test trials. A break was planned halfway through the trials and the children were free to have more breaks if needed. In order to maximize the children's attention to trials, the experimenter controlled the presentation of the next item after

\section{4}



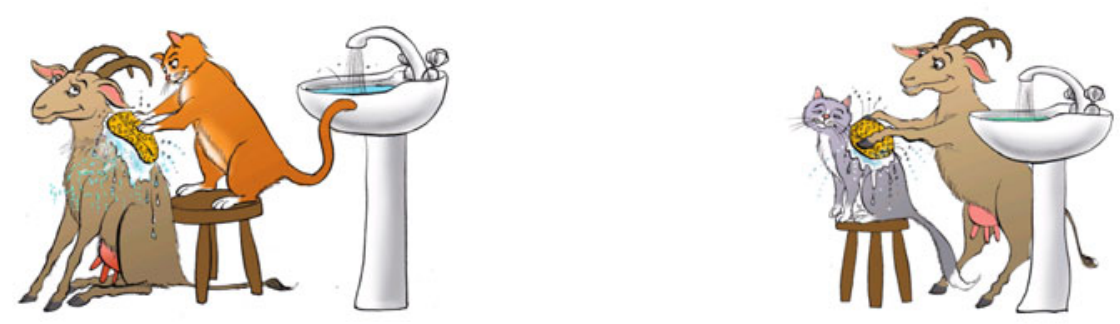

Fig. 2. Target responses.

each response by clicking the mouse. The administration of the whole experiment took approximately 30-40 minutes per participant.

\section{Response type coding}

Children's responses were scored according to one of four categories, one of which was the target response and the remaining were errors. Examples in (7) are target responses for $\mathrm{SS}$ and $\mathrm{SO}$ respectively, and the relevant pictures are illustrated in Figure 2.

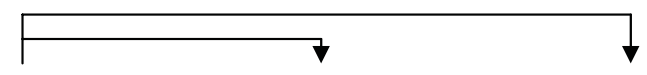

(7) a. The cat [that $<$ cat $>$ is washing the goat] has climbed onto the stool

b. The cat [that the goat is washing <cat $>$ ] has climbed onto the stool $\boldsymbol{A}$

The arrows in (7) and in the examples below indicate which DP is the subject of each verb it is connected to, as they were depicted in the pictures. They are meant to help the reader to understand how we constructed distracters, but they do not indicate a relation between moved constituents and their copy in the original position.

Examples in (8) through (I0) illustrate the three error categories. For both sentence types ( $\mathrm{SS}$ and $\mathrm{SO}$ ), three error categories are created on the basis of how children interpret the relation between subject and object DPs and verbs. The first error category is MAIN CLAUSE error (= MCE), where only the subject-verb relation in the embedded verb is interpreted correctly. A non-target response is categorized as $\mathrm{MCE}$, if the chosen picture depicted the following relations, (8a) for SS and (8b) for SO (see Figure 3 for the corresponding pictures). 

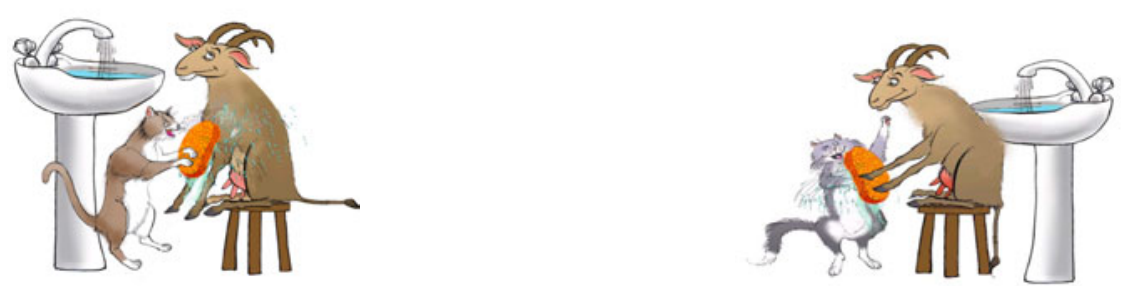

Fig. 3. Main Clause Error (MCE).

(8) a. The cat [that <cat $>$ is washing the goat] has climbed onto the stool

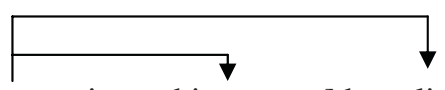

b. The cat [that the goat is washing <cat $>$ ] has climbed onto the stool

Note that, in the SS sentence, the MCE means that participants rely on the linear order of constituents to interpret subject-verb relations.

The second error category was RELATIVE CLAUSE ERROR (=RCE), where only the subject-verb relation in the main clause is interpreted correctly. A non-target response was categorized as RCE if the chosen picture depicted the following DP/verb relations, (9a) for an SS and (9b) for an SO (see Figure 4 for the corresponding pictures).

(9) a. The cat [that <cat> is washing the goat] has climbed onto the stool

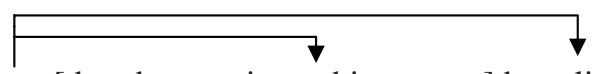

b. The cat [that the goat is washing <cat>] has climbed onto the stool

The last category was DOUBLE CLAUSE ERROR (=DCE), where both subjectverb relations are erroneously interpreted. An error was categorized as DCE, if the chosen picture depicted the following relations, (roa) for an SS and (rob) for an SO (see Figure 5).

(10) a. The cat [that $<$ cat $>$ is washing the goat] has climbed onto the stool

b. The cat [that the goat is washing <cat>] has climbed onto the stool 

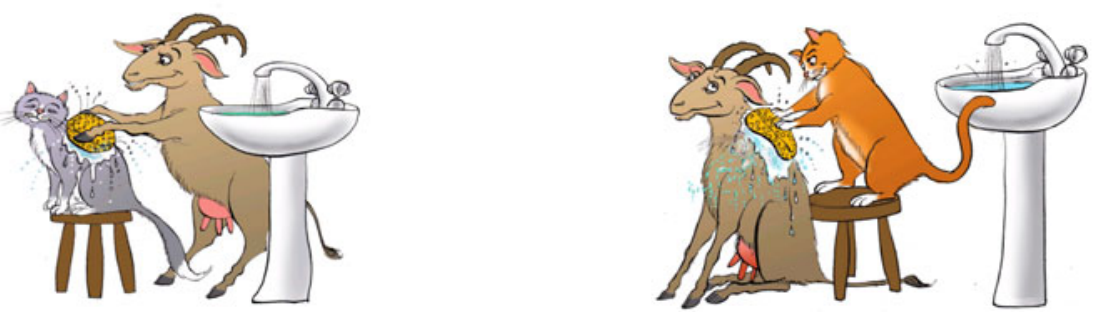

Fig. 4. Relative Clause Error (RCE).

SS

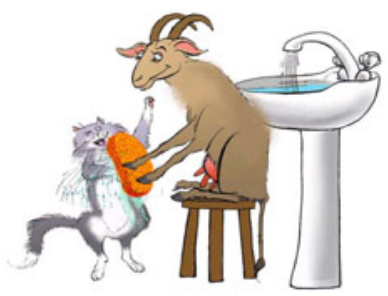

SO

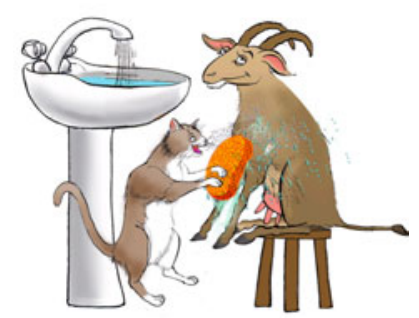

Fig. 5. Double Clause Error (DCE).

DATA ANALYSIS

The mean frequencies for the different response types for each condition and each group are presented in Table $4 .{ }^{3}$ We used a repeated measure logistic regression model to analyze the results. The dependent variable (Response type) is a categorical factor with four levels (Correct, Main Clause Error (MCE), Relative Clause Error (RCE), Double Clause Error (DCE)), which are not independent as only one of the four categories can be chosen in each trial. Because of the statistical dependency of responses, we obtained the logistic regression parameters and the associated inferential tests with GEE methodology (Liang \& Zeger, I 986), as implemented by the SAS system. First, we compared the response accuracy between the two lists. The factor List did not yield any significant difference $\left(\chi^{2}(\mathrm{r}, \mathrm{N}=\mathrm{I} 728)=0.23, p=0.63\right)$. Hence, we can safely assume that the responses of the subjects did not differ

[3] Standard deviations do not appear in the table, given that our dependent variable is categorical (rather than continuous). This also justifies the use of a logistic regression model to estimate the response frequencies. 
TABLE 4. Mean frequencies (expressed in percentages) for the experimental conditions for the three subject groups ${ }^{\mathrm{a}}$

\begin{tabular}{|c|c|c|c|c|c|c|c|c|c|c|c|c|c|}
\hline \multirow{2}{*}{$\begin{array}{l}\text { Sentence } \\
\text { type }\end{array}$} & \multirow[b]{2}{*}{ DP match } & \multicolumn{4}{|c|}{ G-SLI N= 12} & \multicolumn{4}{|c|}{ GRAMMAR $\mathrm{N}=\mathrm{I} 2$} & \multicolumn{4}{|c|}{ VOCABULARY $\mathrm{N}=\mathbf{I} 2$} \\
\hline & & $\mathrm{C}$ & MCE & $\mathrm{RCE}$ & DCE & $\mathrm{C}$ & MCE & $\mathrm{RCE}$ & DCE & $\mathrm{C}$ & MCE & $\mathrm{RCE}$ & DCE \\
\hline \multirow[t]{2}{*}{ SS } & $\mathbf{M}$ & $60 \cdot 4$ & $27 \cdot 1$ & $8 \cdot 3$ & $4 \cdot 2$ & $79 \cdot 2$ & 9 & $6 \cdot 9$ & $4 \cdot 9$ & $8 \mathrm{I} \cdot 3$ & II $\cdot I$ & $4 \cdot 9$ & $2 \cdot 8$ \\
\hline & $\mathbf{M M}$ & $75 \cdot 7$ & $20 \cdot 8$ & $2 \cdot 8$ & 0.7 & $85 \cdot 4$ & 9 & $2 \cdot 8$ & $2 \cdot 8$ & $92 \cdot 4$ & $2 \cdot 8$ & $4 \cdot 2$ & 0.7 \\
\hline \multirow[t]{2}{*}{ so } & $\mathbf{M}$ & $38 \cdot 9$ & I9:4 & I $6 \cdot 7$ & 25 & $5^{6 \cdot 9}$ & 9 & $22 \cdot 9$ & II $\cdot I$ & $55 \cdot 6$ & II $\cdot$ I & $20 \cdot I$ & 13.2 \\
\hline & $\mathbf{M M}$ & $47 \cdot 2$ & $14 \cdot 6$ & $22 \cdot 9$ & I $5 \cdot 3$ & $64 \cdot 6$ & II $\cdot$ I & I 8.8 & $5 \cdot 6$ & $67 \cdot 4$ & I I $\cdot 8$ & I $7 \cdot 4$ & $3 \cdot 5$ \\
\hline
\end{tabular}

Notes: C: correct; MCE: Main Clause Error; RCE: Relative Clause Error; DCE: Double Clause Error; SS: subject relative clauses; SO: object relative clauses; M: Match; MM: Mismatch; ${ }^{a}$ Within each group, $\mathrm{C}+\mathrm{MCE}+\mathrm{RCE}+\mathrm{DCE}$ add up to $100 \%$. 
RELATIVE CLAUSE COMPREHENSION, NUMBER, SLI, AND SYNTAX

TABLE 5. Parameter values for fixed effects in mixed logistic regression model of accurate response proportions, expressed in odds ratios

\begin{tabular}{|c|c|c|c|c|}
\hline Parameter & Estimate & $\chi^{2}$ & Df & $p$ \\
\hline Sentence & $0 \cdot 29$ & I8.33 & I & $<.001$ \\
\hline Match & $\mathrm{I} \cdot 75$ & I $2 \cdot 82$ & I & $<\cdot 001$ \\
\hline Group & - & $9 \cdot 39$ & 2 & .000 \\
\hline Group, contrast G-SLI/GRAMMAR & $2 \cdot$ II & $5 \cdot 19$ & I & .066 \\
\hline Group, contrast G-SLI/VOCABULARY & $2 \cdot 65$ & 13.04 & I & .001 \\
\hline Group, contrast GRAMMAR/VOCABULARY & $\mathrm{I} \cdot 25$ & 0.39 & I & n.s. \\
\hline
\end{tabular}

NOTE: None of the other main effects or 2 nd or 3 rd order interactions is significant.

in the two lists. Hence, we collapsed the factor List in the following analyses.

\section{Accuracy analysis}

In order to determine if the groups' responses differed on SS and SO and on the Match and Mismatch conditions, the first model contrasted target and non-target responses (which add up to I00\% of subjects' responses). Table 5 reports the estimated coefficient and its level of significance for each fixed factor (in odds ratios).

The significant parameter estimates associated with the fixed factors Sentence and Match indicate that SS conditions and mismatch conditions significantly increased the odds of a correct response. The main effect of Group was also significant. The follow-up group contrasts showed that the performance of the G-SLI group was significantly less accurate than the Vocabulary control groups, but there was no significant difference between G-SLI/grammar control groups or between grammar control/vocabulary control groups.

In summary, the accuracy analysis revealed that SS sentences are more accurate than SO sentences. Thus, our findings support the subject-object asymmetry previously reported in the literature. Moreover, the mismatch conditions are more accurate than match conditions, in both sentence types and for all groups. The group of children with G-SLI performed less accurately on this task than the vocabulary control group. However, the difference did not reach the significance level $(p=66)$ when comparing the G-SLI and grammar control groups.

\section{Non-target response analysis}

In order to determine if there were group differences in non-target responses, we compared the following three models, i.e., Main Clause Error 
ADANI $E T A L$.

TABLE 6. Parameter values for fixed effects in mixed logistic regression model of non-target response proportions, expressed in odds ratios

\begin{tabular}{|c|c|c|c|c|c|c|c|c|c|c|c|c|}
\hline \multirow[b]{2}{*}{ Parameter } & \multicolumn{4}{|c|}{$\begin{array}{c}\text { MCE vs. RCE } \\
\quad \mathrm{N}=35^{\mathrm{a}}\end{array}$} & \multicolumn{4}{|c|}{$\begin{array}{l}\text { MCE vs. DCE } \\
\qquad \mathrm{N}=35^{\mathrm{b}}\end{array}$} & \multicolumn{4}{|c|}{$\begin{array}{l}\text { RCE vs. DCE } \\
\quad \mathrm{N}=33^{\mathrm{c}}\end{array}$} \\
\hline & Estimate & $\chi^{2}$ & Df & $p$ & Estimate & $\chi^{2}$ & Df & $p$ & Estimate & $\chi^{2}$ & Df & $p$ \\
\hline Sentence & $3 \cdot 36$ & $8 \cdot 54$ & I & .003 & $4 \cdot 18$ & 10.2 & I & $.00 \mathrm{I}$ & $I \cdot 3 I$ & 0.57 & I & n.s. \\
\hline Match & $0.9 \mathrm{I}$ & 0.17 & I & n.s. & 0.44 & $6 \cdot 14$ & I & .013 & 0.48 & $6 \cdot 36$ & I & .02 \\
\hline $\begin{array}{l}\text { Sentence } \\
\text { by group }\end{array}$ & - & $2 \cdot 90$ & 2 & n.s. & & $6 \cdot 19$ & 2 & .045 & - & $3 \cdot 56$ & 2 & n.s. \\
\hline
\end{tabular}

NOTES: MCE: Main Clause Error; RCE: Relative Clause Error; DCE: Double Clause Error; ${ }^{\text {a }}$ one grammar-matched child is excluded due to absence of MCE or RCE responses; ${ }^{b}$ one grammar-matched child is excluded due to absence of MCE or DCE responses; ${ }^{c}$ two grammar-matched children and one vocabulary-matched child are excluded due to absence of RCE or DCE responses; none of the other main effects or 2 nd or 3 rd order interactions is significant.

(MCE)/Relative Clause Error (RCE), Main Clause Error (MCE)/Double Clause Error (DCE), and Relative Clause Error (RCE)/Double Clause Error (DCE). Table 6 shows the estimated coefficient and its level of significance for each fixed factor (in odds ratios).

First, we calculated the change of odds for choosing an MCE response rather than an RCE response, for each factor and each group. Table 6 (left panel) shows a main effect of the factor Sentence, which indicates that SS conditions significantly increased the odds of an MCE response. Thus, when non-target responses occurred, the different sentence types were associated with different response strategies. Namely, MCE responses occurred significantly more often in SS sentences, whereas RCE responses occurred significantly more often in SO sentences. The factor Group did not modulate these effects. Second, we calculated the odds change for choosing an MCE rather than a DCE, for each factor and each group. We found significant main effects of the factors Sentence and Match (see Table 6, central panel). These two main effects indicated that SS conditions and mismatch conditions significantly increased the odds of an MCE response. We also found a significant interaction of Sentence $\times$ Group. Multiple contrasts revealed that children with G-SLI had a greater probability of choosing a DCE response in SO conditions, whereas the Grammar and Vocabulary control group did not. Thus, in contrast to grammar and vocabulary controls, the children with G-SLI chose significantly more MCE responses in SS and significantly more DCE responses in SO. Third, we calculated the odds change of choosing an RCE response rather than a DCE response, for each factor and each group. As the right 
panel of Table 6 shows, only the main effect of the fixed factor Match is significant. This main effect indicates that mismatch conditions significantly decreased the probability of a DCE response.

\section{Individual performance}

In addition to the statistical analysis for groups, individual performance is shown in Figure 6 to verify whether our group results are representative of performance across individuals within the group. The top-centre and top-right panels in Figure 6 show that the grammar and vocabulary control participants were overall very accurate in SS. Three out of twenty-four children were exceptions to this pattern (SI3 and $\mathrm{S}_{\mathbf{I}} 6$ in the grammar control group and $\mathrm{S}_{2} 8$ in the vocabulary control group) and showed at least $20 \%$ MCE responses. In contrast, MCE responses in SS were consistently attested in nine out of twelve children with G-SLI, as indicated in the top-left panel in Figure 6 (the remaining 3 children reach $90 \%$ correct in SS conditions). Turning to SO sentences (bottom panels in Figure 6), four children in the Grammar control group and two in the Vocabulary control group were around $90 \%$ accurate. None of the children in the G-SLI group reached this performance level. Among the grammar control participants that were below a cut-off point of $90 \%$ accurate, six out of eight chose predominantly RCE responses, one child chose $\mathrm{RCE}$ and $\mathrm{DCE}$ responses to the same extent, and one child $\left(\mathrm{S}_{25}\right)$ chose MCE responses. As for the vocabulary control group, among the ten children who are less than $90 \%$ accurate, six children consistently chose RCE responses; one child ( $\left.\mathrm{S}_{3} \mathrm{I}\right)$ chose $\mathrm{RCE}$ and DCE responses to the same extent; another child ( $\left.\mathrm{S}_{34}\right)$ chose $\mathrm{RCE} / \mathrm{MCE} / \mathrm{DCE}$ responses to the same extent; and only two children out of ten showed a preference for MCE responses, when they failed to choose the target picture. Hence, the majority of TD children who choose a wrong answer tend to misinterpret the grammatical relation within the $\mathrm{RC}$ and choose the reversed animal character(s) as agent(s) of the embedded verb. In contrast, within the group of children with G-SLI, it is not possible to identify a response strategy that children prefer over other strategies. As shown in the bottom-left panel in Figure 6, each child with G-SLI performs very differently from the other ones in the group.

In summary, a detailed inspection of individual performances revealed that a minority of the children did not behave in accordance with the group results. Importantly, this holds for children with G-SLI as well as TD children. However, we think that this divergent behaviour of some participants is ultimately the manifestation of an expected heterogeneity that affects these populations, and this is exactly the reason why inferential statistics are useful in these cases. 


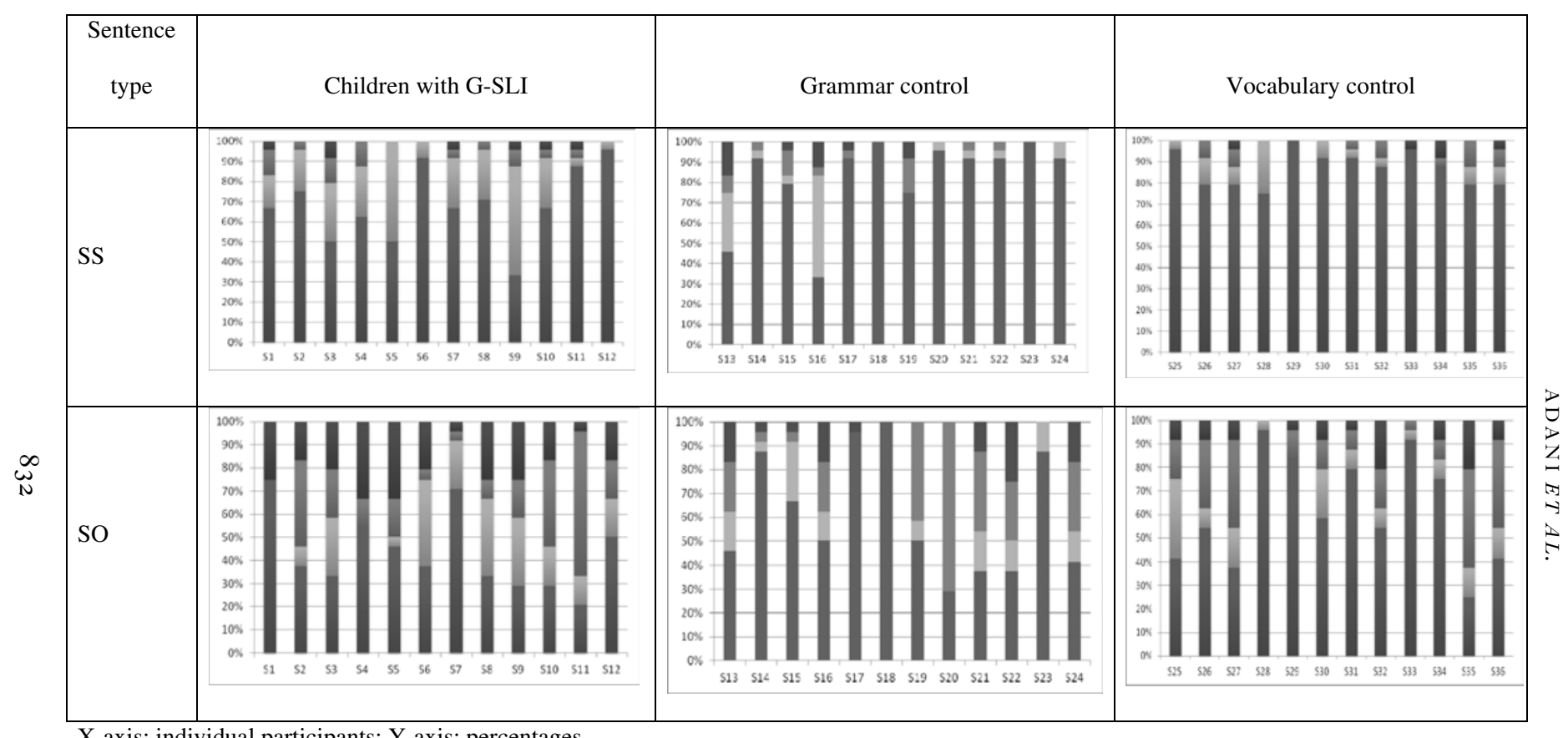

X-axis: individual participants; Y-axis: percentages.

Legend: $\square$ Correct $\square$ MCE $\square$ RCE $\square$ DCE.

Fig. 6. Individual performances on SS (top panel) and SO (bottom panel). 
DISCUSSION

Comprehension of SS and SO with matching and mismatching number features on subject and object DPs was assessed in a group of children with G-SLI and two groups of younger TD children. Our main finding is that correct RC interpretation was facilitated by DP number dissimilarities for children with G-SLI, just as for TD children. That is, where one DP was singular and the other one was plural, performance was significantly more accurate than in those conditions where both DPs had the same number, for all groups of children. Furthermore, children with G-SLI performed significantly less accurately than TD vocabulary controls on both $\mathrm{SS}$ and $\mathrm{SO}$, a response pattern that is often reported in the existing cross-linguistic literature. Analysis of non-target responses revealed that, if children with G-SLI fail to choose the target answer, they often rely on the linear word order of constituents when interpreting SS (a strategy used significantly less often by TD children). However, they do not show a preferred strategy in SO. In contrast to the children with G-SLI, both groups of TD children tend to choose the RCE error in SO (i.e., they tend to interpret SO as SS).

We will now discuss our findings in the light of the existing psycholinguistic approaches to RC difficulty and to language impairment in $(\mathrm{G}-)$ SLI presented at the beginning of the paper.

\section{Number dissimilarity effects in RC comprehension in children with G-SLI}

A number of recent psycholinguistic studies investigating on-line processing, production, or comprehension abilities in adults and TD children have shown that RC difficulty can be modulated in experimental contexts. As discussed in the 'Introduction', these effects can be traced back to the nature of linguistic constituents that appear in the sentence. It is now established that object RCs with two full DPs are harder to interpret than object RCs where one argument is a full DP and the other is a pronoun, a proper name, a quantified expression, or another nominal constituent of a different structural type (Arnon, 2010; Friedmann et al., 2009; Gordon et al., 200I) and that feature dissimilarity also plays a role (Adani et al., 2010). These results are supported by our findings on TD children. Furthermore, we discovered that the same facilitation was evident in children with G-SLI.

Difficulties in RC comprehension in children with SLI are well documented in the literature. Some studies capitalize on the fact that object RCs impose a particular difficulty for children with SLI (Friedmann \& Novogrodsky, 2004), but most studies also show that subject RC comprehension and production are not intact in SLI (Håkansson \& Hansson, 2000; Schuele \& Nicholls, 2000; Stavrakaki, 2002). In our study, children with G-SLI (mean age: I2; I I) performed significantly less accurately on both SS and SO when compared to receptive-vocabulary TD controls (mean 
age: 8 ; $)$, but the difference did not reach significance level with the grammar control group (mean age: $6 ; 9$ ). We found that despite a general overall poorer performance, children with G-SLI are above chance on both SS and SO sentences, and they used number information in a similar way to TD children. The two factors Match and Group never interacted in the analysis of accuracy or in the analysis of non-target responses. Therefore, despite their clear difficulties in computing the movement operations that are necessary to interpret RCs, children with G-SLI are able to make use of other morphological cues that facilitate their comprehension. So, what are the consequences of these results?

We argue that the ability to compute movement-derived dependencies is defective in children with G-SLI, but the computations of relations that are established via specifier-head agreement (within the DP or within the clause) are spared. Furthermore, the ability to compute agreement relations within the DP and via spec-head can actually be used by children with G-SLI to overcome some of their difficulties with movement. Thus, our results support the CGC hypothesis (van der Lely, 2005) and they also corroborate existing findings by Jakubowicz (2003) and Stavrakaki and van der Lely (2010) as knowledge of subject-auxiliary verb agreement is not affected in (G-)SLI.

The above-chance performance on both SS and SO is explained using the notion of 'movement optionality' (van der Lely, I998), according to which 'movement is a free choice' (p. i 80) in the grammar of children with G-SLI. This contrasts with adult grammar and the grammar of TD children, where checking features via movement is an obligatory operation. In this respect, our proposal differs from both Stavrakaki's (2002) and Friedmann and Novogrodsky's (2004, 2007) proposals on the underlying nature of syntactic deficits in children with SLI. Stavrakaki (2002) observed below-chance performance on the production of both object wh-questions and RCs, which is explained as absence of movement operations in the grammar of Greek-speaking children with SLI. Such chance performance on $\mathrm{SS}$ and $\mathrm{SO}$ is not found in our results, thus indicating the optional availability of this grammatical operation in English-speaking children with G-SLI. It is possible that Stavrakaki's young subjects had yet to learn such compensation, giving the appearance of the absence rather than the optionality of movement. Friedmann and Novogrodski (2004, 2007) argue that the syntactic deficit on movement-derived sentences affects the ability of Hebrew-speaking children with S-SLI to assign thematic roles correctly. The prediction that this hypothesis would make in our experiment is that children with G-SLI should choose the RCE response in SO (thus, interpreting $\mathrm{SO}$ as $\mathrm{SS}$ ). However, this response behaviour was mostly found in the two TD groups. Recent data, however, suggest a different explanation for this so-called 'optionality'. Fonteneau and van der Lely's 
(2008) ERP data indicated that G-SLI children use different neural mechanisms to interpret sentences; specifically those associated with semantic rather than syntactic processing. They suggested that their teenage participants with G-SLI were thus compensating for their syntactic deficit semantically. A hint that this might also be what is happening in our data comes from the inspection of non-target responses that children with G-SLI gave when they interpreted SS sentences incorrectly. As is discussed later in this section (cf. (I I) below and the discussion around this error), when children with G-SLI fail to interpret an SS sentence, the majority of them seem to interpret subject-verb relations locally, thus relying on the linear order of constituents. This error might come about because children with G-SLI rely on verb semantics (rather than sentence structure) while interpreting an SS sentence.

Importantly, children with G-SLI's demonstrated ability to use number information correctly might have a valuable implication for therapy: morphological feature dissimilarities among them, number dissimilarities on nouns and verbs can be made prominent in order to facilitate sentence comprehension. In the light of the promising results reported by Levy and Friedmann (2009), we would like to suggest that number dissimilarities on nouns and verbs could also be used to make the relations between a verb and its arguments more explicit in children where implicit knowledge of verb argument structure is significantly impaired. Furthermore, number dissimilarities could also be introduced in a more advanced phase of the therapy, for instance when explicit teaching of wh-movement takes place. This could be used with centre-embedded RCs, similar to the ones that we have investigated in our study of children with G-SLI. These sentences present two lexical verbs (one in the main clause and one in the embedded one) and two potential candidates as arguments (the subject and the object DPs). Centre-embedded RCs are notoriously harder than right-branching RCs for adults (Gibson, I 998) and for children (Corrêa, I 995). In these harder cases, we therefore suggest that the use of additional morphological markers to identify the grammatical relations between sentential constituents might be fruitful in early therapeutic stages. Further intervention studies are needed to test whether such therapy is effective. If this prediction is supported, this intervention concept could be applied to the comprehension of other types of constructions (object wh-questions, cleft sentences) in the future.

In the rest of this section we will discuss the patterns of non-target response that were identifiable through our four-picture experimental set-up, and how these response patterns elucidate the existing knowledge on $\mathrm{RC}$ comprehension difficulties in TD children and children with SLI. These commentaries are based on the results of the group statistical analysis, although intra-individual differences were identified in the three groups of children, as discussed above. 
The non-target response that both groups of TD children predominantly chose when they failed to pick the target picture for an SO was the RCE response. This picture depicted an action where the subject of the embedded verb was misinterpreted as its object. Thus, the RC head was interpreted as the subject of the main verb as well as subject of the embedded verb. This error ultimately corresponds to interpreting an SO as an SS. The tendency of young TD children to interpret object RCs as subject RCs is a robust finding attested across studies, both in production (Belletti \& Contemori, 20ı ; Diessel \& Tomasello, 2000; Guasti \& Cardinaletti, 2003; Novogrodsky \& Friedmann, 2006; Stavrakaki, 2002; Zukowski, 2008) and in binary-picture-sentence-matching tasks (Arosio, Adani \& Guasti, 2009; Contemori \& Garraffa, 20 Io; Friedmann \& Novogrodsky, 2004; Friedmann et al., 2009). Our study shows that TD children tend to interpret an object $\mathrm{RC}$ as a subject $\mathrm{RC}$ even when more alternative pictures are available to them, thus indicating that this is not a task-dependent response but a genuine strategy. Following Grillo (2008) and Friedmann et al. (2009), we interpret the difficulty with object $\mathrm{RC}$ as due to the requirement to interpret the relationship between the $\mathrm{RC}$ head and its copy in merge position, crossing the embedded subject DP. The embedded subject is a nominal constituent of a structural type similar to the moved constituent and thus it acts as a potential candidate of the movement relationship (Rizzi, 2004). The effect of the intervening subject in object RC is usually observed up to age four years, whereas older children perform significantly more accurately (Adani, 20I I). All TD children included in our sample were older than five (their ages ranged between 6 ; 0 and 8 ; i I), so they are not expected to make such errors. However, in contrast with most of the cited articles, in our study only centre-embedded RCs were tested. Our finding concurs with other published work showing that older children (8-io years) are not yet performing at ceiling on RCs (Arosio, Guasti \& Stucchi, 20 I I; Guasti \& Cardinaletti, 2003; MacDaniel, McKee \& Bernstein, I 998). Hence, it is not surprising that older children show difficulties which are analogous to those of younger children when tested on the most taxing structure.

Moving to G-SLI, children with this impairment chose the MCE 24\% of the time (on average for the match and mismatch conditions) on SS sentences. This response only appears around $8 \%$ of the time in the two groups of TD children. Furthermore, inspection of individual performances revealed that nine out of twelve children with G-SLI choose the MCE response consistently in $\mathrm{SS}$, whereas only three out of twenty-four TD children showed a similar response pattern. The example in (I I) illustrates the structural relations in the MCE response in SS:

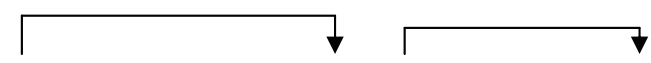

(11) The cat [that $<$ cat $>$ is touching the goat] has climbed onto the stool

$$
836
$$


Hence, the attempt to interpret an SS sentence results in a coordinated structure, such as (I2):

(I2) The cat is touching the goat and the goat has climbed onto the stool

Similar heuristic strategies are attested in other studies of children with SLI as well. For example, children with SLI produce simple declarative (Contemori \& Garraffa, 20ı ; Levy \& Friedmann, 2009; Stavrakaki, 2002) and coordinated sentences (Levy \& Friedmann, 2009; Stavrakaki, 2002) instead of the more complex RCs. Stavrakaki (2002) relates this non-target response to a last resort processing strategy. We suggest that this error represents an attempt to interpret subject-verb relations as locally as possible on the basis of the linear word order of constituents, thus ignoring the presence of clause boundaries.

Similar to the case of SS sentences, there is also a divergence between children with G-SLI and TD children in non-target SO responses. Whereas TD children tend to choose the RCE, the responses of children with G-SLI are distributed across the three error categories: Main Clause Error (MCE: I $7 \%$ ), Relative Clause Error (RCE: 20\%), and Double Clause Error (DCE: $20 \%)$. As we have seen, in TD children, the prominence of RCE responses was linked to the intervening embedded subject, which disrupts the interpretation of SO. Most children with G-SLI do not show this preference for the RCE response. Indeed, it is not possible to identify a specific strategy that is used by children with G-SLI when they fail to interpret an SO. Therefore, we conclude that teenage children with G-SLI are significantly impaired in computing hierarchical structural dependencies for RCs, and moreover do not show any one alternative strategy to resolve this impairment. This can be inferred because they do not show a preference for RCE responses; rather, they all show a different response pattern. On the basis of the results obtained in our task it is not possible to say more about the underlying processes that children with G-SLI are using while parsing an RC. In order to shed more light on these processes, the use of on-line as well as brain-imaging measures is warranted.

We would like to conclude this section with a remark regarding the interaction between comprehension and production data to describe language abilities in children with SLI. Contemori and Garraffa (2010) used production data to argue that 'children with SLI do not use the same facilitative strategies as TD children' (p. I954), although the accuracy scores between the two groups (SLI and TD) did not differ significantly in comprehension. We would like to reinforce and extend the scope of this observation by suggesting that comprehension data can also provide a detailed level of analysis into the potential alternative strategies that children use when comprehension of syntactically complex sentences fails. This is made possible by constructing the experimental material to allow the 
participant to choose from a wider set of alternative responses, as in this study.

\section{CONCLUSIONS}

Our results reveal that RC comprehension is significantly impaired in children with G-SLI in relation to younger language-matched TD children. However, children with G-SLI show a similar sensitivity as TD children to number manipulation. When one DP was singular and the other one was plural, all children were significantly more accurate than in those conditions where both DPs had the same number. We argue that children with G-SLI are able to make use of low-level distinctions (such as number marking on DPs) and to compute local grammatical relations (such as subject-verb agreement). These findings support the CGC hypothesis, which predicts a deficit in the computation of movement derived sentences but a relative strength in the computations of other grammatical relations that do not involve movement of a constituent, such as noun-determiner agreement and subject-verb agreement. We also suggest that this spared ability could be used in therapy to enhance the comprehension of syntactically complex sentences such as RCs and possibly other related constructions (e.g., whquestions and clefts). Due to the intrinsic limitation of our behavioural method and to the apparent intra-individual variability within the three groups of children, it is clear that more investigations, especially those on brain imagining, are warranted in order to more specifically characterize the nature of the deficit in (G-)SLI.

\section{REFERENCES}

Adani, F. (20II). Rethinking the acquisition of relative clauses in Italian: towards a grammatically based account. Fournal of Child Language 38(I), I 4 I-65.

Adani, F., van der Lely, H. K. J., Forgiarini, M. \& Guasti, M. T. (20 го). Grammatical feature dissimilarities make relative clauses easier: a comprehension study with Italian children. Lingua r2o(9), 24 I 8-66.

Arnon, I. (2010). Rethinking child difficulty: the effect of NP type on children's processing of relative clauses in Hebrew. Fournal of Child Language 37(I), 27-57.

Arosio, F., Adani, F. \& Guasti, M. T. (2009). Processing grammatical features by Italian children. In J. M. Brucart, A. Gavarrò \& J. Sola (eds.), Merging features: computation, interpretation, and acquisition. Oxford: Oxford University Press.

Arosio, F., Guasti, M. T. \& Stucchi, N. A. (20 I I). Disambiguating information and memory resources in children's processing of Italian relative clauses. Fournal of Psycholinguistic Research 40(2), I 37-54.

Belletti, A. \& Contemori, C. (2010). Intervention and attraction. On the production of subject and object relatives by Italian (young) children and adults. Paper presented at Language Acquisition and Development: Generative Approaches to Language Acquisition.

Bishop, D. V. M. (1997). Uncommon understanding: development and disorders of language comprehension in children. Hove: Psychology Press. 
Bishop, D. V. M. (2003). Test for Reception of Grammar (TROG-2). London: Harcourt Assessment.

Bortolini, U., Leonard, B. L. \& Caselli, M. C. (r998). Specific language impairment in Italian and English: evaluating alternative accounts of grammatical seficits. Language and Cognitive Processes $\mathbf{1 3}(\mathrm{I}), \mathrm{I}-20$.

Carminati, M. N. (2005). Processing reflexes of the Feature Hierarchy (Person> Number $>$ Gender) and implications for linguistic theory. Lingua II 5, 259-85.

Clahsen, H., Bartke, S. \& Gollner, S. (1997). Formal features in impaired grammars: a comparison of English and German SLI children. Fournal of Neurolinguistics ro(2/3), I 5 I-7I.

Contemori, C. \& Garraffa, M. (20I0). Comparison of modalities in SLI syntax: a study on the comprehension and production of non-canonical sentences. Lingua $\mathbf{1 2 0}(8)$, I $940-55$.

Conti-Ramsden, G. \& Botting, N. (I 999). Classification of children with Specific Language Impairment: longitudinal considerations. Fournal of Speech, Language, and Hearing Research 42, I I 95-204.

Conti-Ramsden, G., Crutchely, A. \& Botting, N. (I997). The extent to which psychometric tests differentiate subgroups of children with SLI. Fournal of Speech, Language, and Hearing Research 4o, 765-77.

Corrêa, L. ( I 995). An alternative assessment of children's comprehension of relative clauses. Fournal of Psycholinguistic Research 24(3), I 83-203.

Diessel, H. \& Tomasello, M. (2000). The development of relative clauses in spontaneous child speech. Cognitive Linguistics II (I/2), I 3 I-5 I .

Dunn, L., Dunn, L., Whetton, C. \& Pintilie, D. (1982). The British Picture Vocabulary Scales. Windsor: NFERNelson.

Fonteneau, E. \& van der Lely, H. K. J. (2008). Electrical brain responses in languageimpaired children reveal grammar-specific deficit. Plos One 3(3), I-6.

Friederici, A. D., Hahne, A. \& Saddy, D. (2002). Distinct neurophysiological patterns reflecting aspects of syntactic complexity and syntactic repair. Fournal of Psycholinguistic Research 3I(I), 46-63.

Friedmann, N., Belletti, A. \& Rizzi, L. (2009). Relativized relatives. Types of intervention in the acquisition of A-bar dependencies. Lingua II9, $67-88$.

Friedmann, N. \& Novogrodsky, R. (2004). The acquisition of relative clause comprehension in Hebrew: a study of SLI and normal development. Fournal of Child Language 3i, $66 \mathrm{I}-8 \mathrm{I}$

Friedmann, N. \& Novogrodsky, R. (2007). Is the movement deficit in syntactic SLI related to traces or to thematic role transfer? Brain $\mathcal{E}$ Language Ior(I), 50-63.

Friedmann, N. \& Novogrodsky, R. (20II). Which questions are most difficult to understand?: The comprehension of Wh questions in three subtypes of SLI. Lingua I2I(3), $367-82$.

German, D. J. (2000). Test of Word Finding, Second Edition (TWF-2): Austin, TX: Pro-Ed.

Gibson, E. (I998). Linguistic complexity: locality of syntactic dependencies. Cognition $\mathbf{6 8}$, I-76.

Gordon, P., Hendrick, R. \& Johnson, M. (200I). Memory interference during language processing. Fournal of Experimental Psychology: Learning, Memory and Cognition 27, I 4 I I -23 .

Grillo, N. (2008). Generalized Minimality: syntactic underspecification in Broca's aphasia. $\mathrm{PhD}$ dissertation distributed by LOT, University of Utrecht, the Netherlands.

Guasti, M. T. \& Cardinaletti, A. (2003). Relative clause formation in Romance child's production. Probus I5, 47-89.

Håkansson, G. \& Hansson, K. (2000). Comprehension and production of relative clauses: a comparison between Swedish impaired and unimpaired children. Fournal of Child Language 27, 31 3-33.

Jakubowicz, C. (2003). Computational complexity and the acquisition of functional categories by French-speaking children with SLI. Linguistics 4I(2), I 75-2 I I. 
Jakubowicz, C. \& Tuller, L. (2008). Specific language impairment in French. In D. Ayoun (ed.), Studies in French applied linguistics, 97-ı33. Amsterdam: John Benjamins Publishing Company.

Leonard, B. L. (1998). Children with Specific Language Impairment. Cambridge: MA: MIT Press.

Leonard, B. L., McGregor, K. K. \& Allen, G. D. (I992). Grammatical morphology and speech perception in children with Specific Language Impairment. Fournal of Speech, Language, and Hearing Research 35, 1076-85.

Levy, H. \& Friedmann, N. (2009). Treatment of syntactic movement in syntactic SLI : a case study. First Language 29( I), I 5-50.

Liang, K. Y. \& Zeger, S. L. (I986). Longitudinal data analysis using generalized linear models. Biometrika 73, I3-22.

Marinis, T. \& van der Lely, H. K. J. (2007). On-line processing of wh-questions in children with G-SLI and typically developing children. International Fournal of Language Communication Disorders 42(5), 557-82.

Marshall, C. R. \& van der Lely, H. K. J. (2007). The impact of phonological complexity on past tense inflection in children with Grammatical-SLI. Advances in Speech-Language Pathology 9, I 9I-203.

McDaniel, D., McKee, C. \& Bernstein, J. B. (I 998). How children's relatives solve a problem for Minimalism. Language 74(2), 308-34.

Novogrodsky, R. \& Friedmann, N. (2006). The production of relative clauses in syntacticSLI : a window to the nature of the impairment. Advances in Speech-Language Pathology 8(4), 364-75.

Oetting, J. B. \& Rice, M. L. (I993). Plural acquisition in children with specific language impairment. Fournal of Speech and Hearing Research 36, I236-48.

Pawlowska, M., Leonard, L. B., Camarata, S. M., Brown, B. \& Camarata, M. N. (2008). Factors accounting for the ability of children with SLI to learn agreement morphemes in intervention. Fournal of Child Language 35, 25-53.

Raven, J. C. (I 998). Raven's progressive matrices. Oxford: Oxford Psychologists Press.

Rice, M. L. \& Wexler, K. (I996). Toward tense as a clinical marker of Specific Language Impairment in English-speaking children. Fournal of Speech and Hearing Research 39 I 239-57

Rizzi, L. (I990). Relativized Minimality (Vol. I6): Cambridge, MA: MIT Press.

Rizzi, L. (2004). Locality and left periphery. In A. Belletti (ed.), Structure and beyond, 223-5 I. New York: Oxford University Press.

Schneider, W., Eschman, A. \& Zuccolotto, A. (2002). E-Prime user's guide. Pittsburgh: Psychology Software Tools Inc.

Schuele, C. M. \& Nicholls, L. M. (2000). Relative clauses: evidence of continued linguistic vulnerability in children with specific language impairment. Clinical Linguistics and Phonetics 14(8), 563-85.

Semel, E., Wiig, E. H. \& Secord, W. A. (1995). Clinical Evaluation of Language Fundamentals (CELF): San Antonio: Psychological Corporation.

Stark, R. E. \& Tallal, P. (I98I). Selection of children with Specific Language Deficits. Fournal of Speech and Hearing Disorders 46, I I 4-22.

Stavrakaki, S. (200I). Comprehension of reversible relative clauses in Specifically Language Impaired and normally developing Greek children. Brain and Language 77, 4I 9-3 I .

Stavrakaki, S. (2002). A-bar movement constructions in Greek children with SLI : evidence for deficits in the syntactic component of language. In E. Fava (ed.), Clinical linguistics : theory and applications in speech pathology and therapy, I3 I-53. Amsterdam \& Philadelphia: John Benjamins.

Stavrakaki, S. \& van der Lely, H. (2010). Production and comprehension of pronouns by Greek children with specific language impairment. British Fournal of Developmental Psychology 28(г), г 89-2 г6.

van der Lely, H. K. J. (I996a). Specifically language impaired and normally developing children: verbal passive vs. adjectival passive sentence interpretation. Lingua 98, 243-72. 
van der Lely, H. K. J. (1996b). The Test of Active and Passive Sentences (TAPS). Available at: <www.dlden.org > .

van der Lely, H. K. J. (1997). Advanced Syntactic Test of Pronominal Reference (A-STOP). Available at: <www.dlden.org $>$.

van der Lely, H. K. J. (I998). SLI in children: movement, economy, and deficits in the computational-syntactic system. Language Acquisition: A Fournal of Developmental Linguistics $7(2-4)$, I $6 \mathrm{I}-92$.

van der Lely, H. K. J. (2000). Verb Agreement and Tense Test (VATT). Available at: $<$ www.dlden.org $>$.

van der Lely, H. K. J. (2005). Domain-specific cognitive systems: insight from grammatical specific language impairment. Trends in Cognitive Sciences 9(2), 53-59.

van der Lely, H. K. J. \& Battell, J. (2003). WH-movement in children with GrammaticalSLI : a test of the RDDR hypothesis. Language 79, I 53-79.

van der Lely, H. K. J. \& Stollwerck, L. (1997). Binding principles and grammatical specific language impairment in children. Cognition 62, 245-90.

van der Lely, H. K. J. \& Ullman, M. (200I). Paste tense morphology in specifically language impaired children and normally developing children. Language and Cognitive Processes r6, I 77-2 I 7 .

Zukowski, A. (2008). Elicited production of relative clauses in children with Williams syndrome. Language and Cognitive Processes 24(I), I-43. 